Watabe, Yoichi; Sassa, Shinji

Evaluation of Sedimentation History of Sandbars at Entrance of Lake Tofutsu, Hokkaido, Japan, by MASW Technology

Verfügbar unter / Available at:

https://hdl.handle.net/20.500.11970/100236

Vorgeschlagene Zitierweise / Suggested citation:

Watabe, Yoichi; Sassa, Shinji (2010): Evaluation of Sedimentation History of Sandbars at Entrance of Lake Tofutsu, Hokkaido, Japan, by MASW Technology. In: Burns, Susan E.; Bhatia, Shobha K.; Avila, Catherine M. C.; Hunt, Beatrice E. (Hg.): Proceedings 5th International Conference on Scour and Erosion (ICSE-5), November 7-10, 2010, San Francisco, USA. Reston, Va.: American Society of Civil Engineers. S. 1013-1022. 


\title{
Evaluation of Sedimentation History of Sandbars at Entrance of Lake Tofutsu, Hokkaido, Japan, by MASW Technology
}

\author{
Yoichi Watabe ${ }^{1}$ and Shinji Sassa ${ }^{2}$
}

\begin{abstract}
${ }^{1}$ Leader, Soil Mechanics and Geo-environment Research Group, Port and Airport Research Institute, 3-1-1, Nagase, Yokosuka 239-0826, Japan; watabe@ipc.pari.go.jp

${ }^{2}$ Senior Researcher, Soil Mechanics and Geo-environment Research Group, Port and Airport Research Institute, 3-1-1, Nagase, Yokosuka 239-0826, Japan; sassa@ipc.pari.go.jp
\end{abstract}

\begin{abstract}
A significant development of sandbars can be seen at the entrance of Lake Tofutsu, one of the lagoons located along the Okhotsk Sea in Hokkaido, Japan. The purpose of this study is to investigate the sequential sedimentation history of these sandbars. We examined the shear-wave velocity and stiffness structures of these sandbars using a surface wave method called the multichannel analysis of surface waves (MASW) in order to identify and describe the stratigraphy of the sediments at the entrance of Lake Tofutsu. We discovered that even though the sandbars appear to be composed of the same sandy material, the subsoil under the sandbars has a very varied sedimentation stratigraphy, consisting of muddy soil derived from the upstream of the lake and sandy soil derived from the coastal sand of the Okhotsk Sea. On the basis of the shear-wave velocity structure obtained in this study, we successfully determined the sequential sedimentation process.
\end{abstract}

\section{INTRODUCTION}

A significant development of sandbars can be seen at the entrance of Lake Tofutsu (Figure 1), one of the lagoons located along the Okhotsk Sea in Hokkaido, Japan. This entrance is located at $43^{\circ} 57^{\prime} 10^{\prime \prime} \mathrm{N}$ and $144^{\circ} 21^{\prime} 34^{\prime \prime} \mathrm{E}$. It is speculated that the sandbars have developed because of the transportation of sediments from the river mouth by the back current of the river. The dike at the river mouth was straightened using a sheet pile wall more than 10 years ago in order to prevent erosion; hence, a back current tends to be created more easily when a storm occurs during a flood tide. If the lake entrance is blocked by sandbars, there is a risk that fishing boats will not be able to pass through it. In addition, the lake environment may be damaged by the rise in the water level, desalination of the lake water, blocking of the fish-way, and declining water quality, despite Lake Tofutsu being registered with the Ramsar Convention.

The formation and migration of sandbars have conventionally been studied by hydrodynamic approach. However, Sassa and Watabe (2009) demonstrates that the sandbar morphodynamics are in fact the interplay between hydrodynamics and geodynamic effects, which are reflected in their sedimentation history. The objective of this study is to identify and describe the sedimentation history, which should be the consequence of erosion and sedimentation of the sandbars, in order to understand the sequential sedimentation process. This can be achieved by applying 


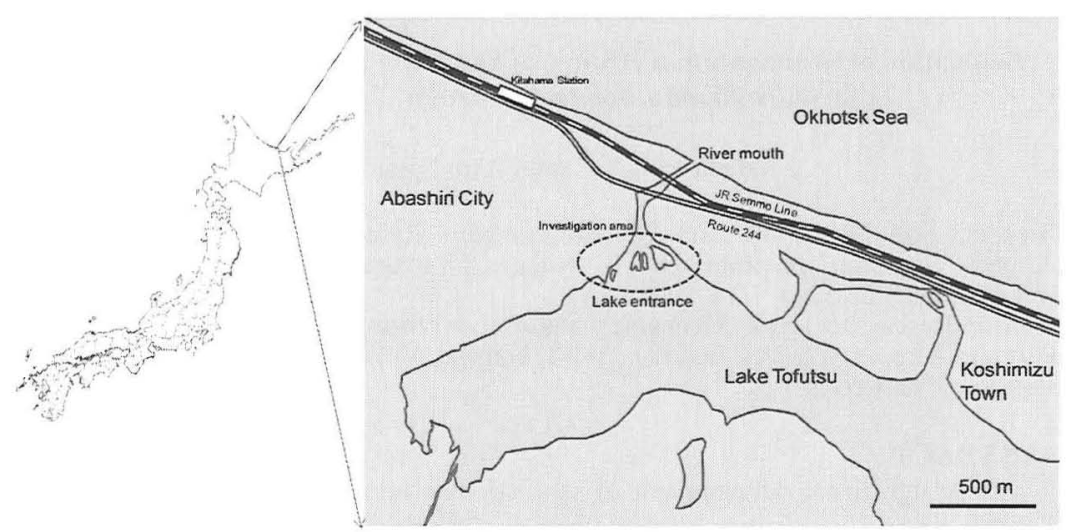

Figure 1. Map of Lake Tofutsu.

multichannel analysis of surface waves (MASW) technology, a useful technology for geophysical exploration.

The MASW technology used in this study was developed by Park et al. (1999) and Hayashi and Suzuki (2004). The authors have applied MASW technology to various types of intertidal flats such as sandy, muddy, and sand-mud layered flats, and have confirmed that this technology is very useful for efficiently surveying the stratigraphy of various types of intertidal flats (Watabe and Sassa, 2008).

\section{SITE INVESTIGATION}

MASW was performed on the sandbars during a low-tide period when the sandbars were exposed in the spring tide on July 3 and 4, 2008. Along the Okhotsk Sea in Hokkaido, tidal variation is characterized by diurnal fluctuation as opposed to semidiurnal fluctuation during a spring tide. The diurnal difference between high and low tides at the Okhotsk Sea around the site was approximately $1.4 \mathrm{~m}$; however, the diurnal difference in Lake Tofutsu is smaller because of the bottleneck effect at the lake entrance.

The location of the entrance of Lake Tofutsu is shown in Figure 1. The distance from the lake entrance to the river mouth is approximately $400 \mathrm{~m}$. A railway and roadway were constructed on the coastal sand bank, which is situated between the sea and the lake. The MASW surveys were conducted along arrays A-F on the sandbars at the lake entrance, as shown in Figure 2. The arrays were mainly along the longitudinal direction of each sandbar; a part of array B was along the transverse direction of the corresponding sandbar. The outlines of both grassy areas and the sandbars at the low-tide period were obtained using global positioning system (GPS) measurement; these outlines are shown in Figure 2. In addition, the elevations along the arrays were leveled, and the results were reflected in the figures of the shearwave velocity structure. Array $\mathrm{C}$ was located in a small rise with grasses, and array $\mathrm{E}$ was located in a small paddock on the lakeside. 


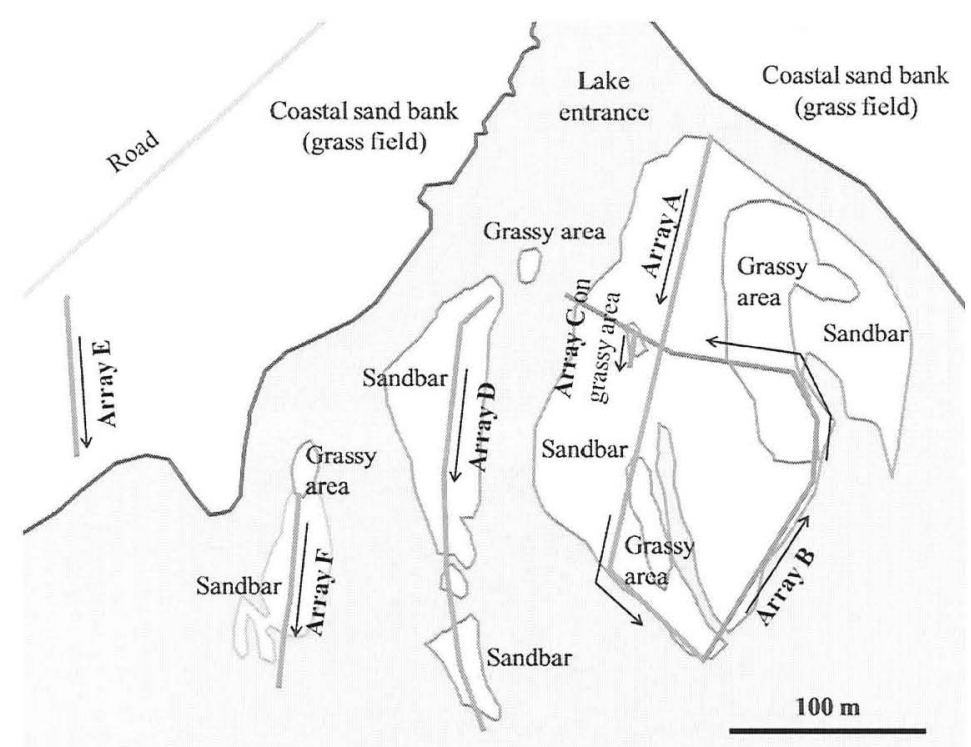

Figure 2. Exposed area of sandbars at lake entrance and arrays for MASW measurement.

The measurement principle of the MASW and the instruments (seismograph: McSEIS-SXW, OYO Corporation, Tokyo, Japan; geophone: GS-11D, OYO Geospace Corporation, Houston, Texas, USA) used in the present study are schematically illustrated in Figure 3. At the site, we used a land streamer (Inazaki, 1999) comprising 24 geophones on aluminum plates aligned in series at $1-\mathrm{m}$ intervals along two parallel ropes on the ground surface. Prior to each measurement, the land streamer was moved by a distance of $4 \mathrm{~m}$. A large portable wooden hammer was used to impose a vertical force on the soil surface at a distance of $0.5 \mathrm{~m}$ from the end of the land streamer, thereby triggering Rayleigh waves in the soil. The propagation of the surface waves thus generated in the soil resulted in the propagation of high-frequency short-wavelength waves in the shallow soil region and low-frequency long-wavelength waves in both the shallow and deep portions of the soil, as is characteristic of Rayleigh waves. The propagation of the Rayleigh waves was measured using the aligned geophones.

The scenes typical of the MASW measurements carried out in this study are shown in Figure 4. The photograph shown in Figure 4(a) depicts the moving of the land streamer and leveling of the ground surface and that shown in Figure 4(b), the triggering of the Rayleigh waves using a wooden hammer. 


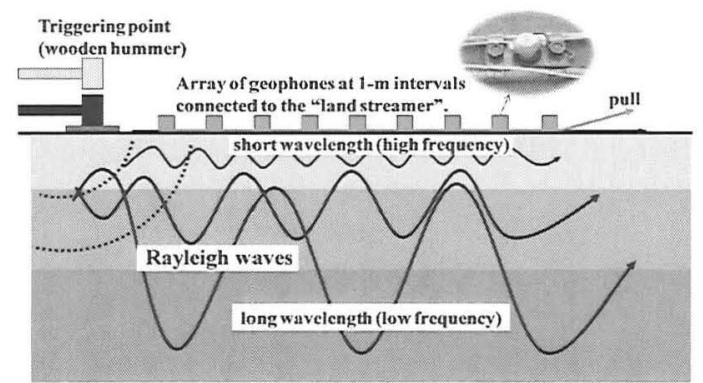

Figure 3. Measurement principle of MASW.

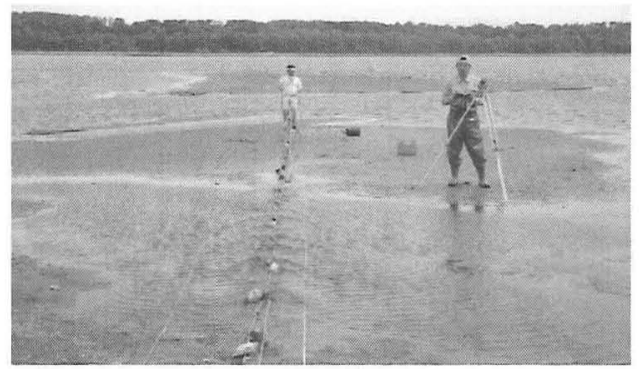

(a) Moving of land streamer and leveling of ground surface (array D).

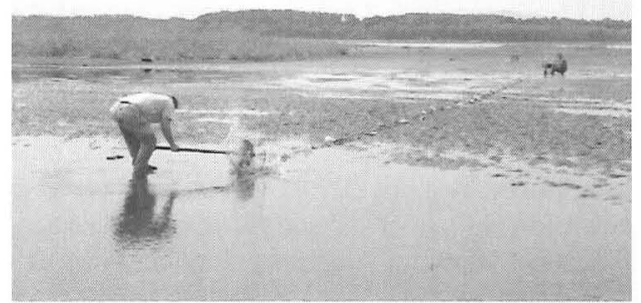

(b) Triggering of Rayleigh waves using a wooden hammer (array A)

\section{Figure 4. Typical scenes of MASW measurement.}

The shear-wave velocity structure can be estimated by the inverse analysis of the various propagation velocities corresponding to the frequencies. In this survey, we obtained the spatial distributions of the surface-wave velocities in the soils and used them to assess the stiffness structures of the sediments under the sandbars. The typical wave patterns corresponding to the various soil types and the algorithm in the calculation are not described here because these details have already been provided 
in the study by Watabe and Sassa (2008).

\section{RESULTS}

The shear-wave velocity structures obtained along the survey arrays are shown in Figure 5. The surface morphology reflects the results of leveling. The shear-wave velocity $v_{\mathrm{s}}$ can be converted to the initial (maximum) shear modulus $G_{0}$ by using the following equation:

$$
G_{0}=\rho_{\mathrm{t}} \times v_{\mathrm{s}}^{2}
$$

where $\rho_{t}$ is the bulk density. Equation 1 indicates that high and low surface-wave velocities correspond to high and low soil stiffness, respectively. It should be noted that the MASW measurement could not be conducted between 165 and $185 \mathrm{~m}$ along array $\mathrm{D}$ because this region was submerged at a certain water depth with a strong current; this can be observed in the exposed sandbar regions in Figure 2 and in the photograph shown in Figure 4(a).

The shear-wave velocity structure at $0-130 \mathrm{~m}$ along array D on a sandbar is similar to that along array $\mathrm{E}$ on the lakeside. Both the regions exhibit a shear-wave velocity of $200-250 \mathrm{~m} / \mathrm{s}$, indicating that the deposit consists of slightly dense and stiff sand. This fact indicates that these regions had been a part of the coastal sand bank. Therefore, it can be hypothesized that the region at $0-130 \mathrm{~m}$ along array $\mathrm{D}$ had been connected to the mainland, even though this region is a part of a sandbar that is separated from the mainland today.

The regions where the deposits are very soft from the surface to the deep portion provide evidence of previous water channels; these regions are at 125-175 m along array $\mathrm{A}$, at around 100-200 $\mathrm{m}$ along array $\mathrm{B}$, at 150-225 $\mathrm{m}$ along array $\mathrm{D}$, and at $20-90 \mathrm{~m}$ along array $\mathrm{F}$. The regions along arrays $\mathrm{A}, \mathrm{D}$, and $\mathrm{F}$ have very soft deposits and a shear-wave velocity lesser than $100 \mathrm{~m} / \mathrm{s}$, whereas the region along array B does not have such soft deposits and has a shear-wave velocity of around 150 $\mathrm{m} / \mathrm{s}$. These facts indicate that the former are clayey deposits derived from the upstream of the lake, and the latter is a silty sand deposit transported from the river mouth by the back current.

The shear-wave velocities at around a 2-m depth at 0-175 $\mathrm{m}$ along array A; at around a 4-m depth at $175-300 \mathrm{~m}$ along array $\mathrm{A}$; at around a $4-\mathrm{m}$ depth at $0-50 \mathrm{~m}$, $125-175 \mathrm{~m}$, and $250-275 \mathrm{~m}$ along array $\mathrm{B}$; at around a 4-m depth at $175-225 \mathrm{~m}$ along array $\mathrm{D}$; at around a 4-m depth at around $0 \mathrm{~m}$ on array $\mathrm{F}$; and at around a 2-m depth at 50-75 $\mathrm{m}$ along array $\mathrm{F}$ indicate that the soils at these depths are stiffer than those at greater depths. These stiffer soils are an evidence of sand layers or oyster mats. In fact, several oyster shells were found when the deposits under the lake were excavated.

The shear-wave velocities at the shallower depths along array $\mathrm{C}$ are as low as approximately $80 \mathrm{~m} / \mathrm{s}$; however, it is notable that those at the surface are as high as approximately $150 \mathrm{~m} / \mathrm{s}$. This fact indicates that the sand on the surface is wellcompacted. 

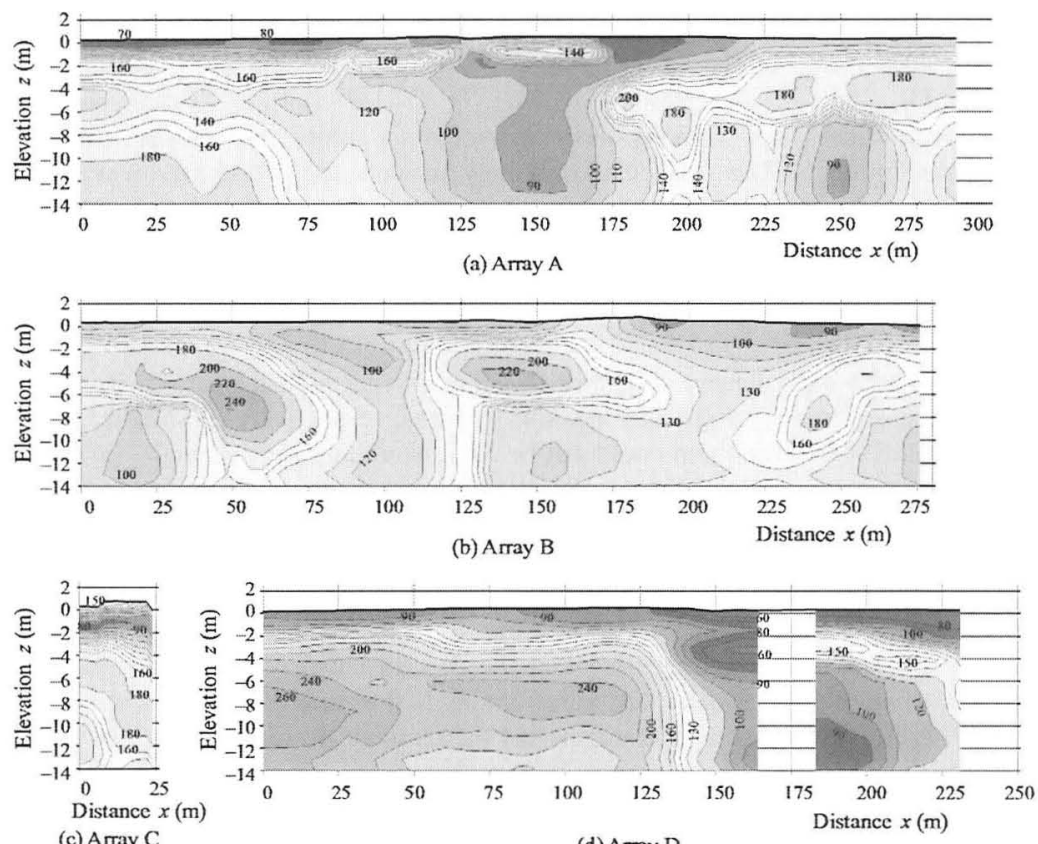

(c) Array C

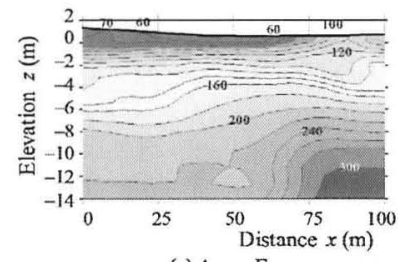

(e) Array E

(d) Array D

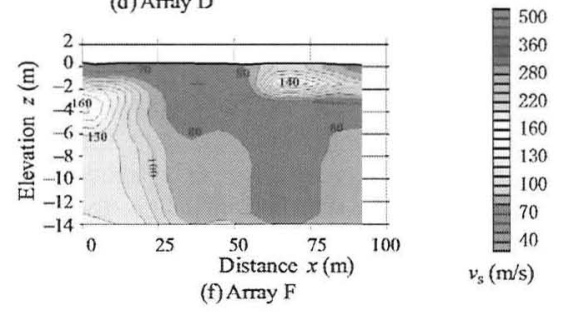

Figure 5. Shear-wave velocity structures obtained by MASW measurement along the survey arrays.

The shear-wave velocity distribution at a $0.5-\mathrm{m}$ depth along the arrays is indicated by color gradation in Figure 6 . All the shear-wave velocities at the sandbar surfaces are evaluated to be lesser than $100 \mathrm{~m} / \mathrm{s}$. It is notable that the surface grasses have no significant effect on the shear-wave velocity distribution. The shear-wave velocity distribution at a 5.5-m depth along the arrays is shown in Figure 7 . In the southern regions of arrays $\mathrm{A}$ and $\mathrm{B}$ and in the northern region of array $\mathrm{D}$, the deposits are slightly stiffer and the shear-wave velocities are greater than $200 \mathrm{~m} / \mathrm{s}$. Around the center of array $\mathrm{A}$ and in the southern regions of arrays $\mathrm{D}$ and $\mathrm{F}$, the deposits are very soft and the shear-wave velocities are in the range of $50-80 \mathrm{~m} / \mathrm{s}$. These deposits 


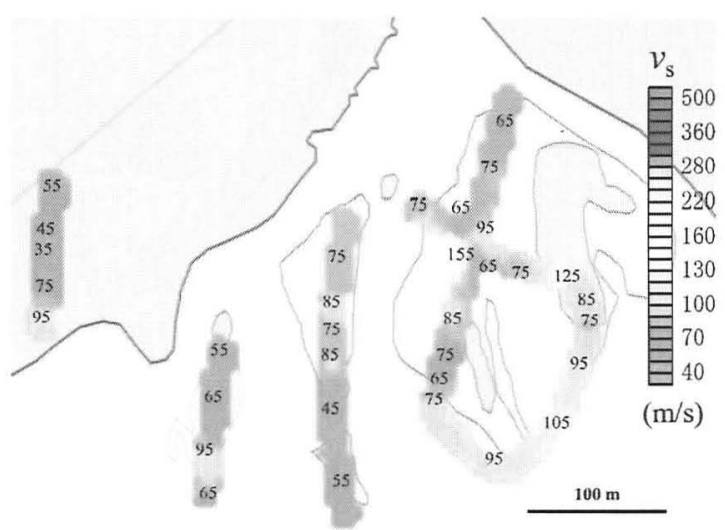

Figure 6. Shear-wave velocity distribution at $0.5-\mathrm{m}$ depth along survey arrays.

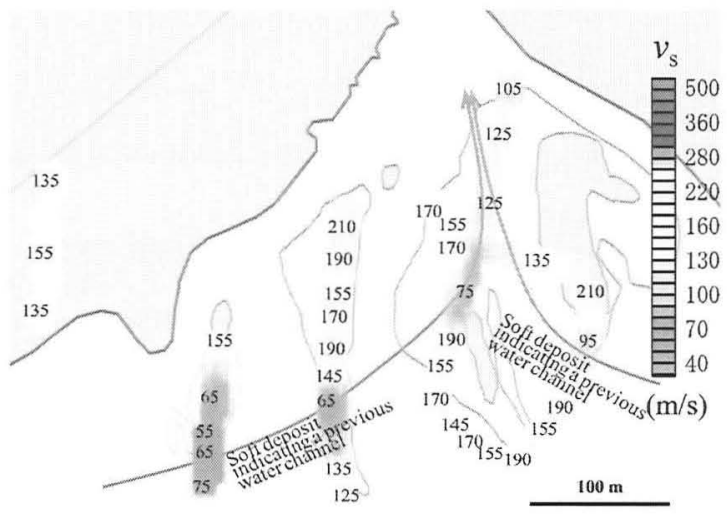

Figure 7. Shear-wave velocity distribution at $5.5-\mathrm{m}$ depth along survey arrays.

indicate that muddy soil was transported from the upstream of the lake, indicating the existence of previous water channels.

All these sandbars appear to be composed of the same deposits with relatively loose and soft sand from the river mouth. However, the shear-wave velocity structure of the sandbars obtained using MASW revealed that these deposits consisted of three layers of different types of soils in a very complicated stratigraphy: (a) dense sand deposited as a coastal sand bank, (b) loose sand rapidly transported from the river mouth by the back current and deposited as sandbars, and (c) very soft muddy soil transported from the upstream of the lake. In other words, even though the sandbars appear to be composed of the same sandy deposit, the subsoil has a very varied stratigraphy. 


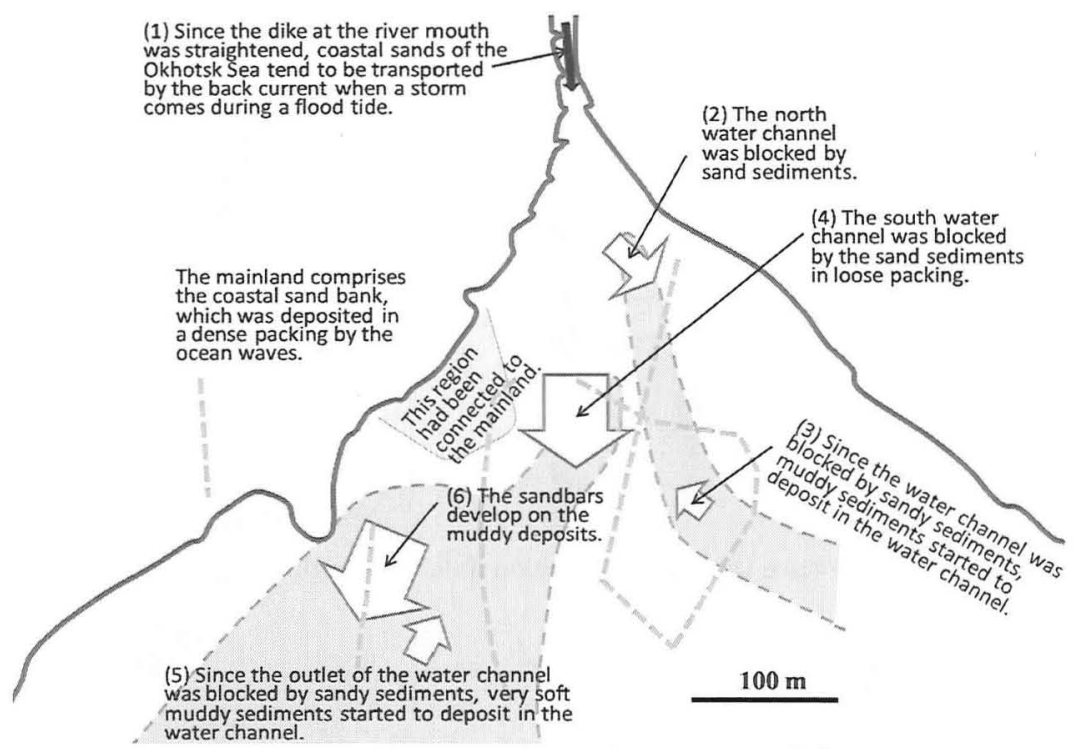

Figure 8. Summary of sandbar formation process at lake entrance.

\section{DISCUSSION: SEDIMENTATION HISTORY AT LAKE ENTRANCE}

On the basis of the shear-wave velocity structures obtained by applying MASW on the sandbars during the exposure period, the sedimentation history of the sandbars at the entrance of Lake Tofutsu is discussed in this section. The summary of the sandbar formation process is shown in Figure 8.

The shear-wave velocity structure of the left side sandbar (array D) is very similar to that of the subsoil on the mainland (array E). This fact indicates that these regions are a part of the coastal sand bank, which had stiff deposits and a high shearwave velocity owing to the effects of ocean waves, currents, and tides. This fact also indicates that the northern region of array D had been previously connected to the mainland as a lakeside.

The two water channels evidenced by MASW in the north and south were very soft from the surface to the deep portion, indicating that the positions of these two water channels were very stable for a long period. This also indicates that appropriate water current to flush away the sediments in the water channels had been maintained from the upstream to the sea through the lake entrance. The positions of the water channels evidenced by MASW are consistent with those observed in an aerial photograph (inset of Figure 9) taken in 1948 before the river mouth dike was straightened.

Since the dike at the river mouth was straightened (Figure 1) about 10 years ago, coastal sands of the Okhotsk Sea tend to be transported by the back current when a storm occurs during a flood tide. Because the back-current velocity suddenly 


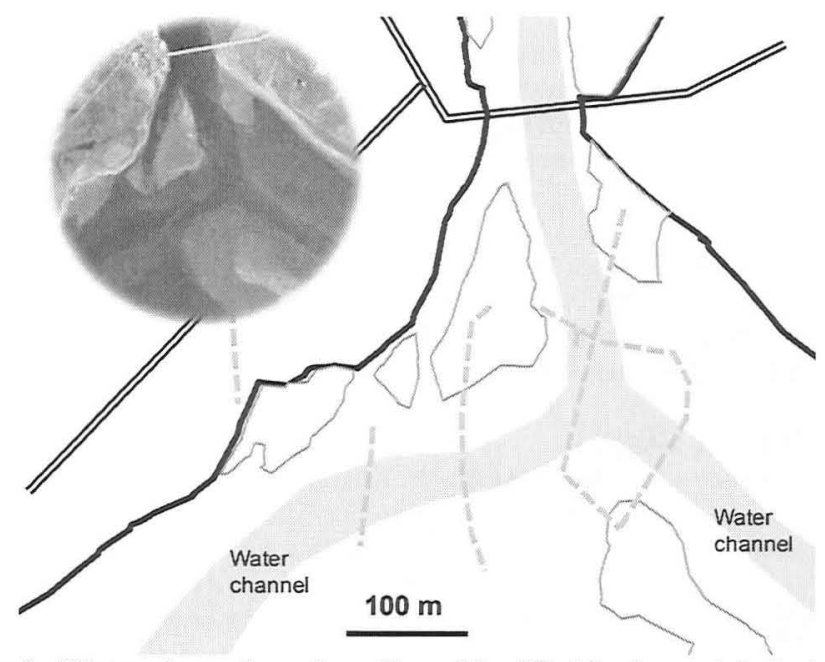

Figure 9. Water channels and sandbars identified in the aerial photograph (inset) taken in 1948.

decreases at the lake entrance where the current is significantly widened, sand particles are rapidly deposited in a loose packing. In fact, the sand deposits are clearly divided into two types: loose and soft deposits corresponding to previous water channels (around $100 \mathrm{~m}$ and $200 \mathrm{~m}$ on array B) and dense sand deposits corresponding to the coastal sand bank (array $\mathrm{E}$ and northern region of array D).

The sands transported by the back current from the coast were first deposited in the north water channel, which was the main stream at that time. Then, the main stream shifted from the north to the south, and consequently, the sands transported by the back current were deposited in the south water channel.

Since the water channels were blocked by the sandbars, muddy sediments transported from the upstream started getting deposited in the previous water channel. The development of the river basin caused a decrease in the river current; this fact should be considered to be a remote cause for the muddy soil deposition.

Presently, the sandbars to the west of the recent main water channel are still developing to upstream of the lake. Consequently, sandbars are developing on the muddy sediments deposited in either the previous water channels or the deeper lake regions seen in array $\mathrm{F}$.

The development of the sandbars is apparently caused only by the sediment transportation by the back current from the river mouth. However, as mentioned above, there is a history of competition between the sandy deposits transported from the coast and the muddy deposits transported from the upstream of the lake. The assessment of the sandbar development on the basis of the MASW results is consistent with an old aerial photograph taken in 1948 (inset of Figure 9) and the memories of the local inhabitants. 


\section{SUMMARY}

In the present study, MASW technology was applied to investigate the sedimentation history of the sandbars deposited at the entrance of Lake Tofutsu in Hokkaido. The results of this investigation indicate that even though the sandbars are apparently composed of the same sandy deposits, the stratigraphy of the subsoil under the sandbars is considerably different. This reflects the sedimentation history as a competition between the sandy sediments transported from the river mouth and the muddy sediments transported from the upstream of the lake. On the basis of the shear-wave velocity structures obtained using MASW, the sedimentation history of the sandbars was successfully sequenced. The sequenced sedimentation history is consistent with an old aerial photograph and the memories of local inhabitants.

\section{ACKNOWLEDGEMENT}

The authors would like to thank Dr. Koichi Hayashi of OYO Corporation for his contribution to the MASW investigation. The field observations were carried out in collaboration with the Abashiri Fisheries Cooperative Association. This study was supported by a Grant-in-Aid for Scientific Research (No. 18360232) from the Ministry of Education, Culture, Sports, Science and Technology, Japan.

\section{REFERENCES}

Hayashi, K. and Suzuki, H. (2004): "CMP cross-correlation analysis of multichannel surface-wave data." Exploration Geophysics, 35, 7-13.

Inazaki, T. (1999): "Land streamer: a new system for high-resolution S-wave shallow reflection surveys." Proceedings of the Symposium on the Application of Geophysics to Engineering and Environmental Problems '99, 207-216.

Park, C.B., Miller, R.D., and Xia, J. (1999): "Multichannel analysis of surface waves." Geophysics, 64(3), 800-808.

Sassa, S. and Watabe, Y. (2009): "Persistent sand bars explained by geodynamic effects." Geophysical Research Letters, 36, L01404, doi:10.1029/2008GL036230.

Watabe, Y. and Sassa, S. (2008): "Application of MASW technology to identification of tidal flat stratigraphy and its geoenvironmental interpretation." Marine Geology, 252, 79-88. 